\title{
Characterization of micro-invasive trabecular bypass stents by ex vivo perfusion and computational flow modeling
}

This article was published in the following Dove Press journal:

Clinical Ophthalmology

II March 2014

Number of times this article has been viewed

\author{
Kendall S Hunter' \\ Todd Fjield ${ }^{2}$ \\ Hal Heitzmann ${ }^{2}$ \\ Robin Shandas' \\ Malik Y Kahook ${ }^{3}$ \\ 'Department of Bioengineering, \\ University of Colorado Denver, \\ Aurora, CO, USA; ${ }^{2}$ Glaukos \\ Corporation, Laguna Hills, CA, USA; \\ ${ }^{3}$ University of Colorado Hospital Eye \\ Center, Aurora, CO, USA
}

\begin{abstract}
Micro-invasive glaucoma surgery with the Glaukos iStent ${ }^{\mathbb{B}}$ or iStent inject $^{\mathbb{B}}$ (Glaukos Corporation, Laguna Hills, CA, USA) is intended to create a bypass through the trabecular meshwork to Schlemm's canal to improve aqueous outflow through the natural physiologic pathway. While the iStent devices have been evaluated in ex vivo anterior segment models, they have not previously been evaluated in whole eye perfusion models nor characterized by computational fluid dynamics. Intraocular pressure (IOP) reduction with the iStent was evaluated in an ex vivo whole human eye perfusion model. Numerical modeling, including computational fluid dynamics, was used to evaluate the flow through the stents over physiologically relevant boundary conditions. In the ex vivo model, a single iStent reduced IOP by $6.0 \mathrm{mmHg}$ from baseline, and addition of a second iStent further lowered IOP by $2.9 \mathrm{mmHg}$, for a total IOP reduction of 8.9 mmHg. Computational modeling showed that simulated flow through the iStent or iStent inject is smooth and laminar at physiological flow rates. Each stent was computed to have a negligible flow resistance consistent with an expected significant decrease in IOP. The present perfusion results agree with prior clinical and laboratory studies to show that both iStent and iStent inject therapies are potentially titratable, providing clinicians with the opportunity to achieve lower target IOPs by implanting additional stents.
\end{abstract}

Keywords: glaucoma, iStent, trabecular bypass, intraocular pressure, ab-interno, CFD

\section{Introduction}

Glaucoma is characterized by progressive optic nerve damage resulting in irreversible loss of vision and is a leading cause of blindness worldwide. ${ }^{1}$ The only available treatment to delay the progression of glaucoma involves lowering the intraocular pressure (IOP). IOP reduction is most commonly accomplished by applying topical medications that reduce the rate of aqueous humor formation or reduce resistance to aqueous humor outflow. ${ }^{2}$ Invasive procedures such as trabeculectomy or glaucoma drainage device implantation are typically performed when medical therapy fails. Despite improvements in glaucoma patient outcomes, compliance to prescribed topical treatments remains an issue, and many surgical procedures are accompanied by significant morbidity. As a result, new micro-invasive techniques and implants capable of providing significant IOP reduction have been developed.

Micro-invasive glaucoma surgery with the Glaukos iStent ${ }^{\circledR}$ and iStent inject $^{\circledR}$ (iStent ${ }^{\circledR}$ is FDA approved in the US, CE marked in the European Union, and has medical device approval in Canada. iStent inject $^{\circledR}$ is an investigational device in the US, and is CE marked in the European Union; Glaukos Corporation, Laguna Hills, CA, USA) is intended to improve physiologic outflow of aqueous humor from the anterior chamber
Correspondence: Malik Kahook University of Colorado Eye Center, 1675 Aurora Ct, Aurora,

CO 80045 , USA

Tel +l 7208482500

Fax +I 7208485014

Email malik.kahook@gmail.com 
through the conventional outflow pathway. ${ }^{3}$ Previous evaluations by an anterior segment perfusion model, ${ }^{4,5}$ flow theory, ${ }^{6}$ and clinical studies, ${ }^{7-13}$ have shown that one or more iStents placed in Schlemm's canal through the trabecular meshwork resulted in lower IOP and reduced medication burden.

The iStent (Figure 1A) was designed to be implanted in Schlemm's canal via an ab-interno procedure through a selfsealing clear corneal incision. The self-trephining tip of the stent pierces the trabecular meshwork, and the curved stent body with retention arches maintains the position of the stent within Schlemm's canal. The open half-pipe design of the stent body assures that the canal remains patent and collector channels are not obstructed. The tubular portion of the stent, the "snorkel," conducts the flow through the trabecular meshwork into Schlemm's canal.

The iStent inject (Figure 1B) was designed to be implanted over a trocar that pierces the trabecular meshwork. The head of the stent facilitates implantation and maintains the position of the stent across the trabecular meshwork. Four side ports are present to direct flow circumferentially into the lumen of Schlemm's canal.

While iStent and iStent inject have been evaluated in the anterior segment perfusion model, ${ }^{4,5}$ the stents have not been previously evaluated in whole eye ex vivo models. Unlike the whole globe model, the anterior chamber model lacks the lens, iris, and choroid which can affect the tension on the scleral spur, and such tension has been shown to affect outflow facility. ${ }^{14-18}$ While the differences in the models were not anticipated to have a large effect on the facility change effected by manipulation of the trabecular meshwork, to verify this assumption the iStent was evaluated in the whole globe model, and the results were compared with Bahler et al. ${ }^{4}$

Engineering approximations (Hagen-Poiseuille) of the resistance through the stents suggest that the resistance is extremely low. The engineering approximations were verified using computational fluid dynamics (CFD), and total outflow resistances with and without stents were calculated.

\section{Methods}

Human globes from pseudophakic donors with no history of glaucoma were obtained from various eye banks around the country. Approval was obtained from the Colorado Multiple Institutional Review Board for the use of human material, and the tenets of the Declaration of Helsinki were followed, prior to initiation of this study. Informed consent was obtained from donors or relatives for use in research by the various eye banks.

The perfusion system (Figure 2) incorporated a standard programmable syringe pump (Pump 11 Plus; Harvard Apparatus, Holliston, MA, USA). Pressure was monitored via an in-line real-time pressure transducer (Research Grade Pressure Transducer; Harvard Apparatus) connected to a single channel chart recorder (Pharmacia REC-481; Pharmacia/Pfizer, New York, NY, USA). Polyethylene tubing with a $1.14 \mathrm{~mm}$ inner diameter (PE-160; Warner Instruments, Hamden, CT, USA) was used for all connections.

The human globe, in each case, was first prepared by injecting Dulbecco's Modified Eagle's Medium (DMEM; Life Technologies, Carlsbad, CA, USA) through the optic nerve with a 26-gauge needle until the globe had returned to a spherical shape. The perfusion system is illustrated in Figure 2. A fluid line (terminating in another 26-gauge needle) was inserted diagonally through the anterior chamber of the eye, passing through the cornea and pupil and ending with the tip beneath the iris (not shown). The globe was surrounded by damp gauze, and the perfusion pump (filled with DMEM) was set to an initial inflow rate of $7 \mu \mathrm{L} /$ minute. IOP was allowed to increase until it reached $30 \mathrm{mmHg}$ to ensure the globe was completely inflated. The infusion rate was then reduced to $2.5 \mu \mathrm{L} /$ minute, and a steady-state IOP was maintained for at least 60 minutes prior to insertion of the devices. The iStent devices were inserted through a clear corneal incision under gonioscopic view. Stent placement was not targeted to any specific features of the trabecular meshwork or Schlemm's canal, although they were implanted on the nasal side to mimic the clinical procedure. When more

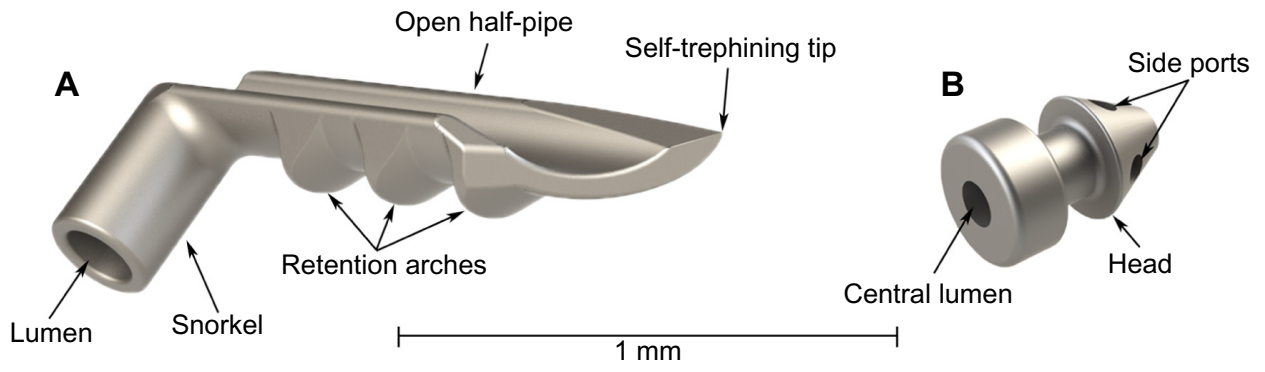

Figure I Illustration of iStent ${ }^{\circledR}$ (Glaukos Corporation, Laguna Hills, CA, USA) (A) and iStent inject ${ }^{\circledR}$ (Glaukos Corporation) (B). 


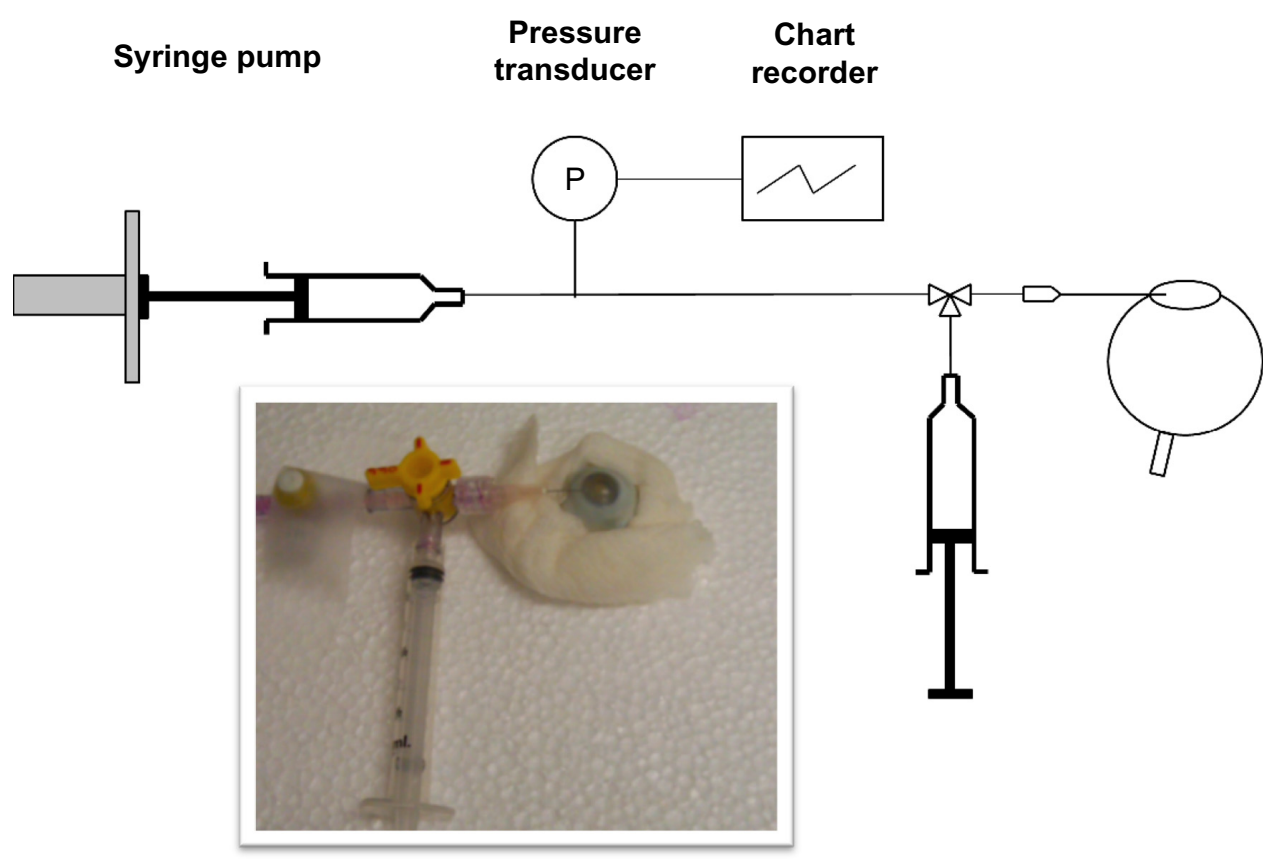

Figure 2 Schematic of perfusion system used for ex vivo studies, with inset photo of setup.

than one stent was inserted, the second stent was placed three clock hours from the first. A water tight closure of the corneal wound was then achieved with a 10-0 nylon suture. The flow rate remained constant, and IOP was measured until steady state was achieved for at least 1 hour post-insertion of the device(s) in all cases in order to determine that the true steady state was achieved.

At low flow rates, the stent resistance, $R_{\mathrm{S}}$, can be estimated using the Hagen-Poiseuille equation, which estimates the resistance through a tubular body. The assumptions of the equation are that the flow is laminar, viscous, and incompressible, and the flow is through a constant circular cross-section where the length of the tube is substantially longer than its diameter. According to Hagen-Poiseuille:

$$
R_{s} \approx 8 \mu L / \pi r^{4},
$$

where $L$ is the length of the tube, $r$ is the radius of the tube, and $\mu=7.2 \cdot 10^{-4} \mathrm{~Pa} \cdot \mathrm{sec}$ is the aqueous humor viscosity at $37^{\circ} \mathrm{C} .{ }^{19}$ The equivalent circuit models used for calculating resistance through the stents are shown in Figure 3. The iStent is a single resistance element calculated via Equation 1, with a length of $250 \mu \mathrm{m}$ and a radius of $60 \mu \mathrm{m}$ : $R_{S} \approx 4.42 \cdot 10^{-3} \mathrm{mmHg} /(\mu \mathrm{L} /$ minute $)$. The iStent inject presents resistance from the central lumen in series with the parallel resistances from the side ports. In this approximation, we assumed that only two side ports were unobstructed by tissue. The central lumen dimensions were approximately
$L=265 \mu \mathrm{m}$ and $r=40 \mu \mathrm{m}$, and the side lumen dimensions were $L=46 \mu \mathrm{m}$ and $r=25 \mu \mathrm{m}: R_{\mathrm{S}} \approx 3.72 \cdot 10^{-2} \mathrm{mmHg} /$ ( $\mu \mathrm{L} /$ minute). The application of Hagen-Poiseuille suggests that the resistance of the iStent is $12 \%$ of the resistance of the iStent inject. Inlet and outlet effects (entrance head loss

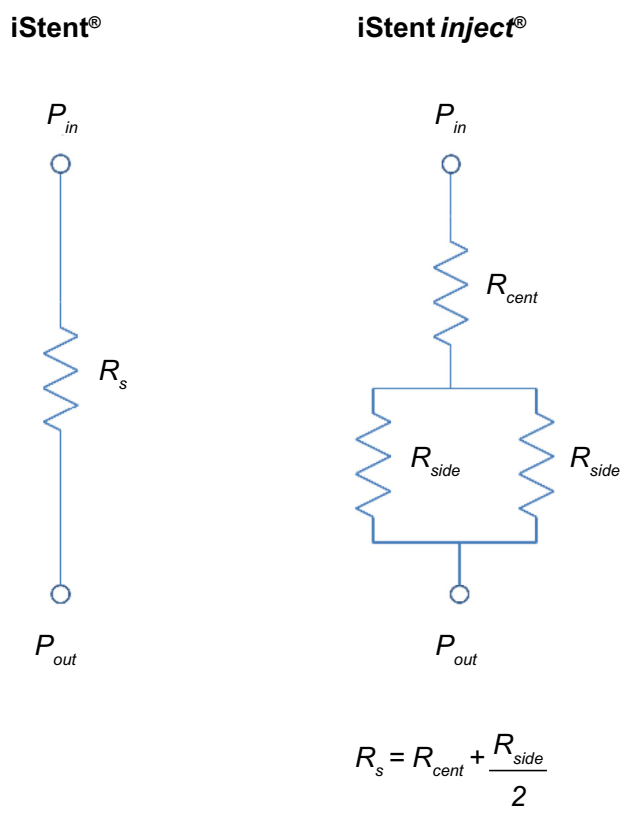

Figure 3 Equivalent circuit models for prediction of resistance through the iStent ${ }^{\circledR}$ and iStent inject ${ }^{\circledR}$ (Glaukos Corporation, Laguna Hills, CA, USA) using the HagenPoiseuille approximation.

Abbreviations: $R$, resistance; $R$, resistance through the stent's snorkel; $P$, pressure; $R_{\text {cent }}$, resistance through the central lumen; $R_{\text {side }}$, resistance through the side lumens; $P_{\text {in' }}$, hydrostatic pressure at the inlet; $P_{\text {out }}$, hydrostatic pressure at the outlet. 
and exit head loss) would be expected to raise the effective resistance somewhat from what is calculated by HagenPoiseuille for both stents. However, as shown below, the flow resistance of both stents is negligible compared with the total outflow resistance of the eye.

CFD models of the two devices were created and solved using the commercial code CFD Research Corporation (ESI Group, Paris, France). Due to the simple geometry of fluid passageway through the iStent, an axisymmetric (two-dimensional) mesh could be used. The mesh included 12,239 two-dimensional elements. For the iStent inject, a three-dimensional mesh was created containing 280,328 three-dimensional hexahedral elements. In preprocessing, the mesh was configured such that only two of the four "side" outlets maintained flow; this assumed that when placed in Schlemm's canal, the other outlets would be blocked by tissue contact. While additional outlets may be unblocked in situ, modeling it in this way represents a worstcase scenario. Aqueous humor is modeled as an incompressible Newtonian fluid with constant dynamic viscosity of $7 \cdot 10^{4} \mathrm{~Pa}$ - sec and density $1.00 \mathrm{~g} / \mathrm{cm}^{3}$.

In this initial application of CFD, we included inlet and outlet regions corresponding to the anterior chamber and Schlemm's canal, respectively. The no-slip condition was applied at the stent and non-inlet/exit surfaces of the anterior chamber inlet section and Schlemm's canal exit section.

Neglecting any uveoscleral flow in the ex vivo whole human eye perfusion model, the outflow resistance is simply calculated per the following equation:

$$
R_{n}=\frac{I O P_{n}}{Q_{a}},
$$

where $R_{n}$ is the total outflow resistance, $I O P_{n}$ is the IOP when $n$ stents are implanted in the eye, and $Q_{a}$ is the total flow into the eye.

\section{Results}

The results from the ex vivo perfusion studies are summarized in Table 1 along with Bahler et al's ${ }^{4}$ data from the anterior chamber model.

A single iStent resulted in a lowering of IOP from baseline in all three eyes tested. The addition of a second iStent to an existing device resulted in additional IOP lowering that was statistically significant.

The nominal rate of aqueous humor production is $2.5 \mu \mathrm{L} /$ minute. ${ }^{20} \mathrm{~A}$ worst-case scenario for examining the performance of the stent, ie, flow rate of $5 \mu \mathrm{L} /$ minute, twice the nominal, was considered. The stent resistances calculated via the Hagen-Poiseuille approximation, shown in Equation 1,
Table I Summary of ex vivo perfusion studies conducted herein in the whole globe model and the data from Bahler et $\mathrm{al}^{4}$ conducted in the anterior segment model

\begin{tabular}{|c|c|c|c|c|c|}
\hline $\begin{array}{l}\text { Device } \\
\text { n=3 each }\end{array}$ & $\begin{array}{l}\text { Baseline } \\
\text { IOP, } \\
\text { mmHg }\end{array}$ & $\begin{array}{l}\text { Final IOP, } \\
\mathrm{mmHg}\end{array}$ & $\begin{array}{l}\Delta \mathrm{IOP}, \\
\mathrm{mmHg}\end{array}$ & $\begin{array}{l}\Delta \text { IOP } \\
P \text {-value }\end{array}$ & $\begin{array}{l}\text { Total } \\
\Delta \mathrm{IOP}, \\
\mathrm{mmHg}\end{array}$ \\
\hline \multicolumn{6}{|c|}{ Whole globe model } \\
\hline Ist iStent & $19.8(2.0)$ & I3.8(0.8) & $6.0(2.2)$ & 0.009 & $6.0(2.2)$ \\
\hline 2nd iStent & I3.8 (0.8) & $10.9(0.9)$ & $2.9(I . I)$ & 0.011 & $8.9(2.2)$ \\
\hline \multicolumn{6}{|c|}{ Anterior segment model ${ }^{4}$} \\
\hline Ist iStent & $19.7(3.5)$ & $13.6(4.1)$ & $6.1(5.4)$ & $<0.05$ & $6.1(5.4)$ \\
\hline 2nd iStent & $13.6(4.1)$ & $10.0(4.3)$ & $3.6(5.9)$ & $<0.05$ & $9.7(5.5)$ \\
\hline
\end{tabular}

Notes: Numbers in parentheses represent standard deviations. The $\triangle \mathrm{IOP}$ column represents the incremental IOP change effected by adding a first or second stent, while the Total $\triangle \mathrm{IOP}$ column represents the total IOP reduction from the no-stent baseline.

Abbreviation: IOP, intraocular pressure.

suggest that a pressure differential of only $0.021 \mathrm{mmHg}$ is sufficient to drive $5 \mu \mathrm{L} /$ minute through the iStent, and only $0.18 \mathrm{mmHg}$ is sufficient to drive $5 \mu \mathrm{L} /$ minute of flow through the iStent inject under the worst-case assumption made above of only two side ports unobstructed. The Hagen-Poiseuille approximations were verified via CFD by applying static pressure differentials to the stents over these ranges.

The steady-state flow of the stent was evaluated with regard to the boundary conditions. These results are shown in Figure 4 and were compared to the expected flow based on the resistance calculated from the Hagen-Poiseuille approximation in Equation 1.

The linearity in Figure 4 indicates that at these flow rates, the resistance was pressure independent, and the actual resistance of the stents was somewhat higher than that approximated by Hagen-Poiseuille. The CFD results indicate that the flow resistance of the iStent is $6.4 \times 10^{-3} \mathrm{mmHg} /(\mu \mathrm{L} /$ minute $)$ and $5.6 \times 10^{-2} \mathrm{mmHg} /(\mu \mathrm{L} /$ minute $)$ for the iStent inject. CFD analysis performed with and without the inlet and outlet regions indicated that much of the increase was due to inlet and outlet flow effects: the pressure loss due to inlet and outlet effects with the iStent was $26.9 \%$, and $18.5 \%$ for the iStent inject. Regardless, the CFD models estimated that a single iStent or iStent inject was wholly sufficient to conduct the entire $2.5 \mu \mathrm{L} /$ minute of aqueous humor production at negligible pressure differentials of only 0.016 and 0.14 $\mathrm{mmHg}$, respectively.

Figure 5 shows a pressure color map through the iStent body generated by the model at a pressure differential of $0.016 \mathrm{mmHg}$, resulting in a flow rate of $2.5 \mu \mathrm{L} / \mathrm{minute}$. Cooler colors indicate lower pressures, while warmer colors indicate higher pressures; the pressure scale, shown above the stent body, indicates color correspondence to pressure in $\mathrm{mmHg}$. 

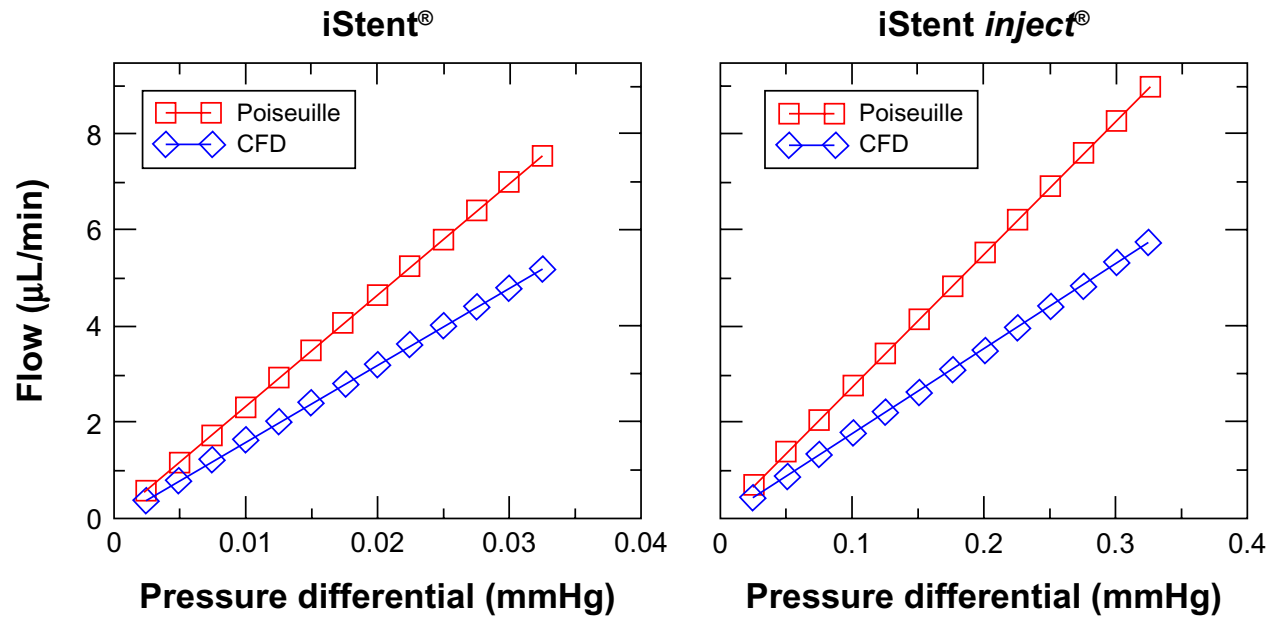

Figure 4 Flow versus pressure for the iStent ${ }^{\circledR}$ and iStent inject ${ }^{\circledR}$ (Glaukos Corporation, Laguna Hills, CA, USA) as calculated by CFD (blue diamonds) and the Hagen-Poiseuille approximation (red squares).

Abbreviation: CFD, computational fluid dynamics; min, minute.

The pressure within the stent transitioned smoothly from the inlet pressure to the outlet pressure, with minimal inlet effects. Maximum axial velocity at the centerline was $0.76 \mathrm{~cm} / \mathrm{second}$, and the maximum Reynolds number was 1.34. These numbers suggest that a laminar flow assumption is correct.

The velocity profiles within the iStent snorkel are shown in Figure 6. A detailed inspection of the flow through the snorkel confirmed that the velocity profile was indeed parabolic (not shown).

Figure 7 shows the pressure differential inside the iStent inject, and Figure 8 illustrates the flow capability of the stent, at a pressure differential of $0.14 \mathrm{mmHg}$, resulting in a flow rate of $2.5 \mu \mathrm{L} /$ minute. As with the iStent, the pressure in the iStent inject transitioned smoothly from the inlet pressure to the outlet pressure, with minimum inlet effects. Maximum axial velocity along the centerline was $1.76 \mathrm{~cm} / \mathrm{second}$, yielding a Reynolds number of 2.01 , and $2.15 \mathrm{~cm} / \mathrm{second}$ at the exit ports, yielding a Reynolds number of 1.54. Again, these numbers indicate that the laminar flow assumption is correct, although some minor additional pressure losses may be associated with secondary (ie, non-axial) velocities seen at the outlet junction on the right-hand side of Figure 8.

Inserting the ex vivo data (Table 1) into Equation 2 , the total outflow resistances calculated with zero, one, and two stents were $R_{0}=7.9 \mathrm{mmHg} /(\mu \mathrm{L} /$ minute $)$, $R_{1}=5.5 \mathrm{mmHg} /(\mu \mathrm{L} /$ minute $)$, and $R_{2}=4.4 \mathrm{mmHg} /(\mu \mathrm{L} /$ minute), respectively.

\section{Discussion}

The current whole globe ex vivo studies verify previous findings that the iStent is an effective IOP lowering device, and that efficacy is enhanced when combining two devices compared with a single device. A single iStent resulted in a pressure reduction of $6.0 \pm 2.2 \mathrm{mmHg}$. The addition of a second stent lowered the pressure by another $2.9 \pm 1.1 \mathrm{mmHg}$

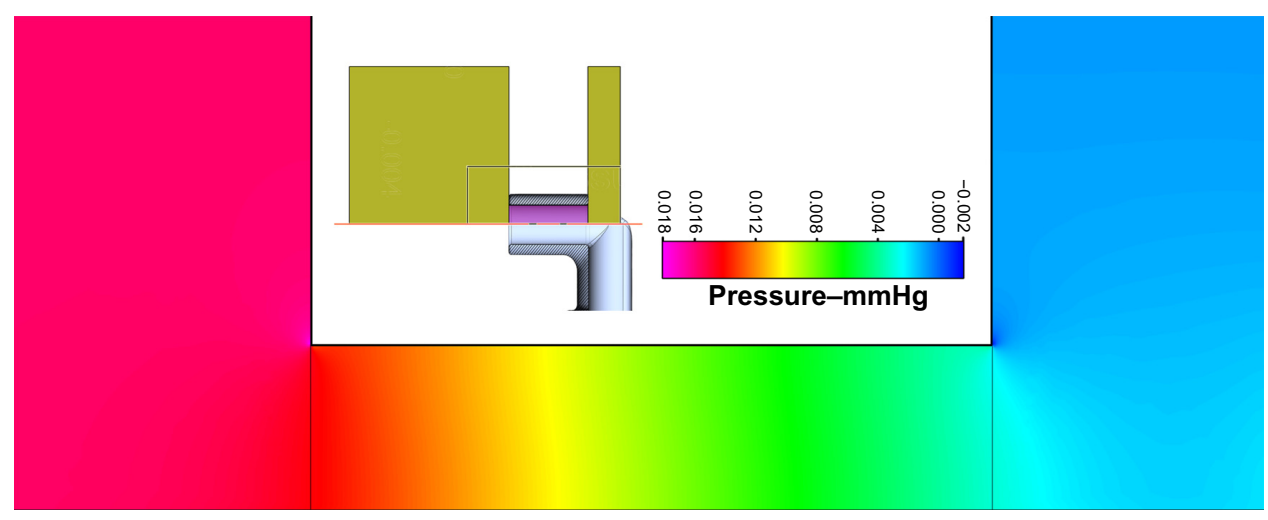

Figure 5 Color map of pressure within a half-section of the iStent ${ }^{\circledR}$ (Glaukos Corporation, Laguna Hills, CA, USA) snorkel at an applied pressure differential of 0.016 mmHg yielding a flow of $2.5 \mu \mathrm{L} /$ minute. The anterior chamber inlet to the snorkel is on the left, and the exit to Schlemm's canal is on the right. 


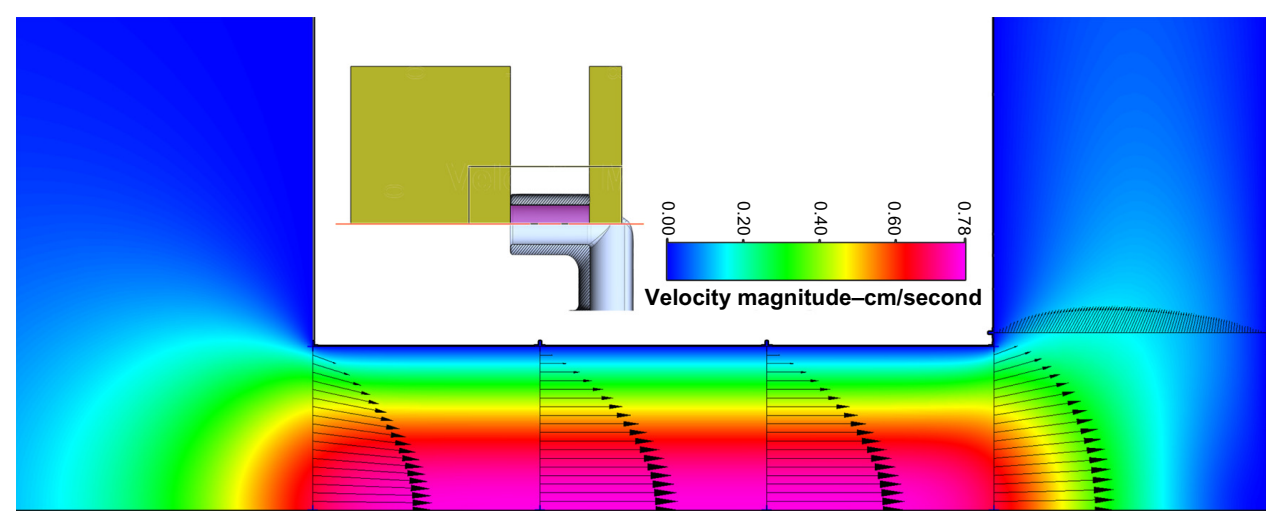

Figure 6 Color map of velocity within a half-section of the iStent ${ }^{\circledR}$ (Glaukos Corporation, Laguna Hills, CA, USA) snorkel at an applied pressure differential of 0.016 mmHg yielding a flow of $2.5 \mu \mathrm{L} /$ minute with overlaid velocity vectors. The anterior chamber inlet to the snorkel is on the left, and the exit to Schlemm's canal is on the right.

to a total pressure reduction of $8.9 \pm 2.2 \mathrm{mmHg}$. These findings agree with perfusion in the anterior segment model, ${ }^{4}$ theoretical analysis, ${ }^{6}$ and clinical studies. ${ }^{7-13}$ Use of an ex vivo model is advantageous because it is fast, inexpensive, and it allows new devices to be tested using the appropriate anatomy prior to clinical studies, especially when the only comparable animal models are primates. The data in Table 1 suggest that either the anterior segment model or the whole globe model is an appropriate ex vivo model for evaluating trabecular meshwork stents.

CFD analysis revealed that flow through the iStent and iStent inject is free of significant resistance, only 0.0062 and $0.057 \mathrm{mmHg} /(\mu \mathrm{L} /$ minute $)$, respectively, at physiological flow rates.

The CFD model assumed unimpeded flow of aqueous humor away from the stent exit. Potential effects of circumferential resistance through Schlemm's canal and distal resistance through the collector channels ${ }^{21}$ are not completely understood and were not incorporated into the CFD model. Instead, experimental data from the ex vivo studies were utilized to evaluate total outflow resistance. Applying Equation 2, the total outflow resistance was calculated to be $R_{0}=7.9 \mathrm{mmHg} /(\mu \mathrm{L} /$ minute $), R_{1}=5.5 \mathrm{mmHg} /(\mu \mathrm{L} /$ minute $)$, and $R_{2}=4.4 \mathrm{mmHg} /(\mu \mathrm{L} /$ minute $)$, for zero, one, and two stents, respectively. Thus, a single iStent reduced the total outflow resistance by $30 \%$, and two iStents reduced the total outflow resistance by $44 \%$. These results agree with previous ex vivo studies. ${ }^{4,22}$

The CFD resistance values are somewhat higher than the resistance predicted by simple circuit models and illustrate the capability of CFD to consider inlet and outlet effects that are often neglected by simpler models. However, the resistance

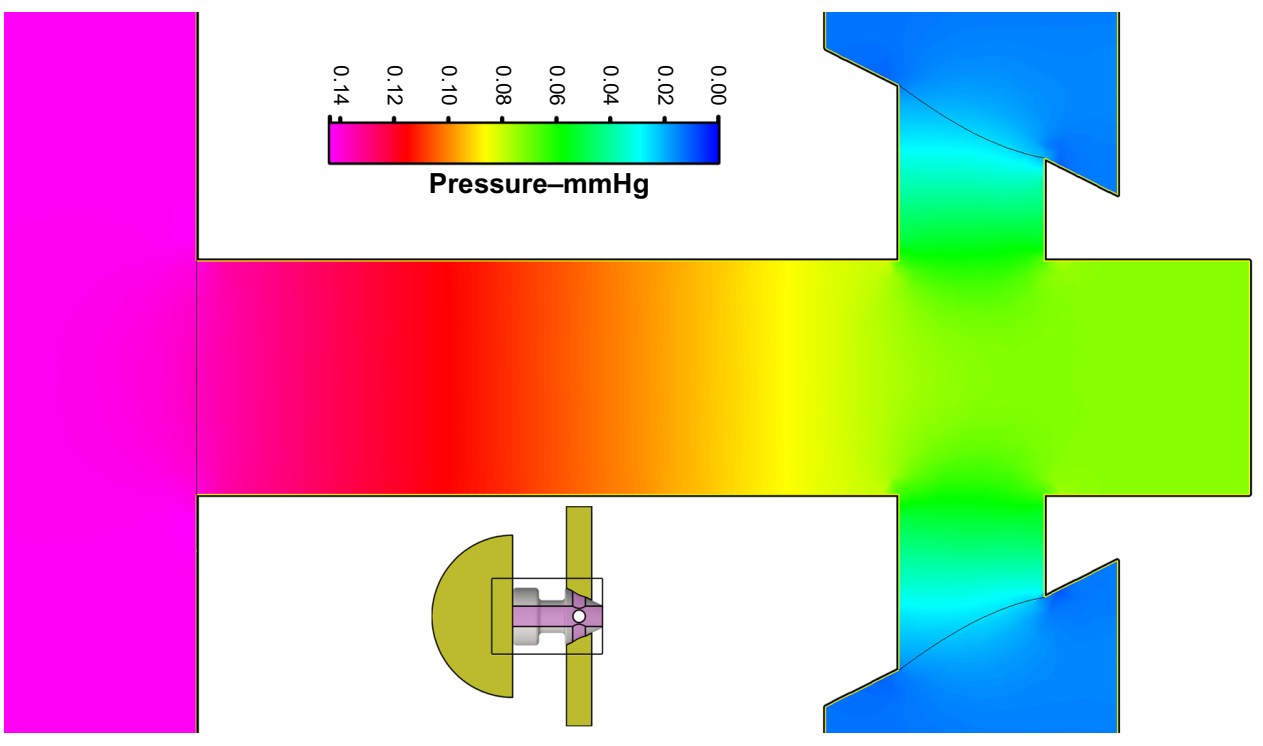

Figure 7 Color map of pressure within the iStent inject ${ }^{\circledR}$ (Glaukos Corporation, Laguna Hills, CA, USA) lumen at an applied pressure differential of 0.14 mmHg yielding a flow of $2.5 \mu \mathrm{L} /$ minute. The anterior chamber inlet to the lumen is on the left, and the side ports exiting to Schlemm's canal are to the right. 


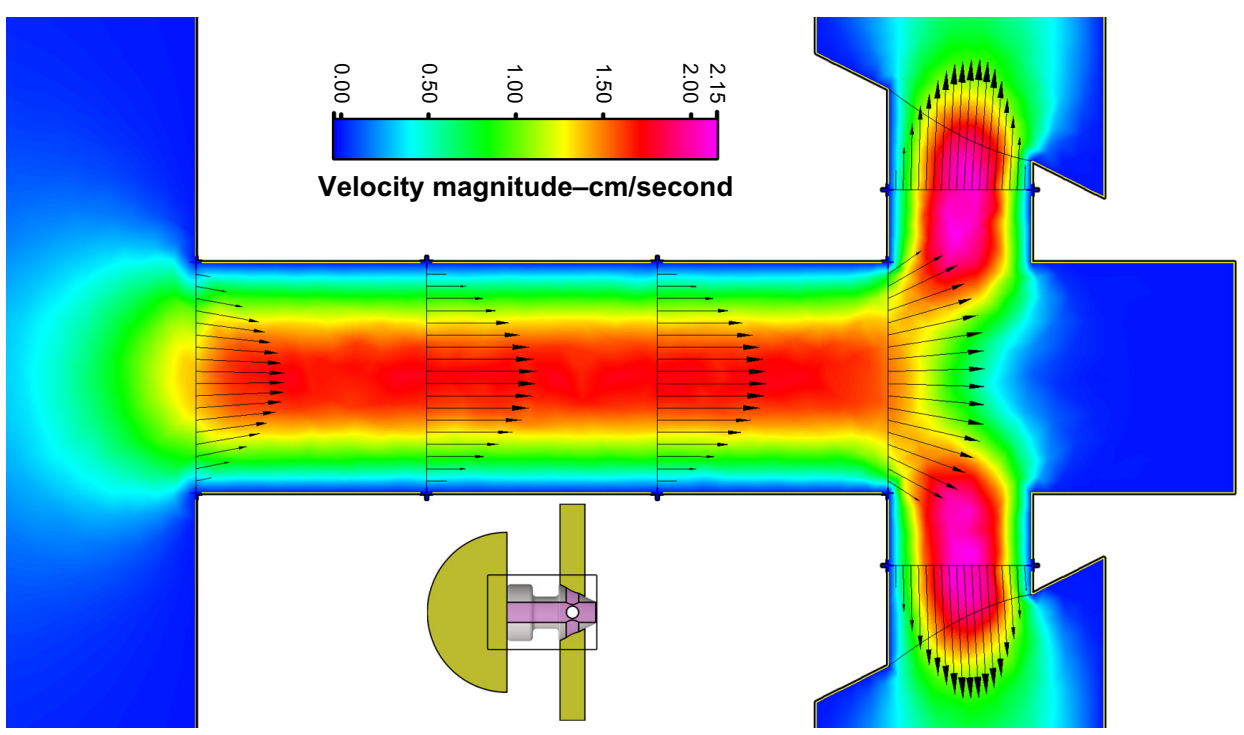

Figure 8 Color map of velocity within the iStent inject ${ }^{\circledR}$ (Glaukos Corporation, Laguna Hills, CA, USA) lumen at an applied pressure differential of 0.14 mmHg yielding a flow of $2.5 \mu \mathrm{L} /$ minute with overlaid velocity vectors. The anterior chamber inlet to the lumen is on the left, and the side ports exiting to Schlemm's canal are to the right.

values are so low that a single iStent is capable of carrying the entire aqueous humor outflow from the anterior chamber into Schlemm's canal at a pressure difference of only $0.016 \mathrm{mmHg}$ or less. The resistance of the iStent is two or three orders of magnitude less than the total outflow resistance. In practice, the aqueous humor outflow utilizes a combination of the iStent, the trabecular meshwork, Schlemm's canal, and the distal outflow pathways. The low resistance of the iStent serves to lower the overall outflow resistance and IOP.

Consistent with the findings of Bahler et al, ${ }^{4}$ adding a second iStent further decreased IOP, probably by accessing additional regions of the distal outflow pathway.

A general limitation of computational and laboratory models is that their results may not exactly represent in vivo outcomes. It is encouraging, therefore, that extensive clinical experience with iStent demonstrates prolonged reduction of IOP and medication burden, combined with an excellent safety profile..$^{7-13}$

\section{Conclusion}

In the whole globe ex vivo model, a single iStent reduced IOP by $6.0 \mathrm{mmHg}$ from baseline, and combination of two iStent implants lowered IOP by $8.9 \mathrm{mmHg}$ from baseline. Despite the micro-size of the iStent and iStent inject trabecular bypass implants, analytical approximations supported by CFD modeling indicated that each stent presented a negligible flow resistance that resulted in significant IOP reduction. CFD modeling also indicated that flow through the iStent and iStent inject lumens was smooth and laminar. These and prior clinical and laboratory studies show that iStent and
iStent inject therapy is potentially titratable, allowing physicians to reach lower target IOPs with the implantation of additional stents.

\section{Acknowledgments}

The work in this paper was performed under a grant by Glaukos Corporation. Todd Fjield and Hal Heitzmann are employees of Glaukos Corporation. Portions of this work were presented at the American Glaucoma Society meeting in 2012 .

\section{Disclosure}

The authors report no conflicts of interest in this work.

\section{References}

1. Resnikoff S, Pascolini D, Etya'ale D, et al. Global data on visual impairment in the year 2002. Bull World Health Organ. 2004;82(11): 844-851.

2. Boland MV, Ervin AM, Friedman D, et al. Treatment for Glaucoma: Comparative Effectiveness. Comparative Effectiveness Review No 60. (Prepared by the Johns Hopkins University Evidence-based Practice Center under Contract No HHSA 290-2007-10061-I.) AHRQ Publication No 12-EHC038-EF. Rockville, MD: Agency for Healthcare Research and Quality. April 2012. Available from: http://www.effectivehealthcare.ahrq gov/ehc/products/183/1024/CER60_Glaucoma-Treatment_20120524. pdf. Accessed January 1, 2014.

3. Saheb H, Ahmed II. Micro-invasive glaucoma surgery: current perspectives and future directions. Curr Opin Ophthalmol. 2012;23:96-104.

4. Bahler CK, Smedley GT, Zhou J, Johnson DH. Trabecular bypass stents decrease intraocular pressure in cultured human anterior segments. Am J Ophthalmol. 2004;138(6):988-996.

5. Bahler CK, Hann CR, Fjield T, Haffner D, Heitzmann H, Fautsch MP. Second-generation trabecular meshwork bypass stent (iStent inject) increases outflow facility in cultured human anterior segments. Am J Ophthalmol. 2012;153:1206-1213. 
6. Zhou J, Smedley GT. A trabecular bypass flow hypothesis. J Glaucoma. 2005;14(1):74-83.

7. Samuelson TW, Katz LJ, Wells JM, Duh YJ, Giamporcaro JE. Randomized evaluation of the trabecular micro-bypass stent with phacoemulsification in patients with glaucoma and cataract. Ophthalmology. 2011;118:459-467.

8. Belovay GW, Nagi A, Chan B, Rateb M, Ahmed II. Using multiple trabecular micro-bypass stents in cataract patients to treat primary openangle glaucoma. J Cataract Refract Surg. 2012;38(11):1911-1917.

9. Fea AM. Phacoemulsification versus phacoemulsification with micro-bypass stent implantation in primary open-angle glaucoma. Randomized double-masked clinical trial. J Cataract Refract Surg. 2010;36:407-412.

10. Craven ER, Katz LJ, Wells JM, Giamporcaro JE. Cataract surgery with trabecular micro-bypass stent implantation in patients with mildmoderate open-angle glaucoma and cataract: two-year follow-up. J Cataract Refract Surg. 2012;38:1339-1345.

11. Arriola-Villalobos P, Martínez-de-la-Casa JM, Díaz-Valle D, Fernández-Pérez C, García-Sánchez J, García-Feijoó J. Combined iStent trabecular micro-bypass stent implantation and phacoemulsification for coexistent open-angle glaucoma and cataract: a long-term study. $\mathrm{Br} \mathrm{J}$ Ophthalmol. 2012;96(5):645-649.

12. Arriola-Villalobos P, Morales-Fernández L, Martínez-de-la-Casa JM, García-Feijoó J. Effects of Glaukos ${ }^{\circledR}$ trabecular stent in the treatment of glaucoma. Eur Ophthalmic Rev. 2013;7(1):10-13.

13. Spiegel D, Wetzel W, Neuhann T, et al. Coexistent primary open-angle glaucoma and cataract: interim analysis of a trabecular micro-bypass stent and concurrent cataract surgery. Eur J Ophthalmol. 2009;19(3): 393-399.
14. Francois J, Rabaey M, Neetens A, Evens L. Further perfusion studies on the outflow of aqueous humor in human eyes. Arch Ophthalmol. 1958:59:683-691.

15. Van Buskirk EM, Grant WM. Lens depression and aqueous outflow in enucleated primate eyes. Am J Ophthalmol. 1973;76: 632-640.

16. Moses RA, Grodzki WJ Jr. Choroid tension and facility of aqueous outflow. Invest Ophthalmol Vis Sci. 1977;16(11):1062-1064.

17. Brubaker RF. The effect of intraocular pressure on conventional outflow resistance in the enucleated human eye. Invest Ophthalmol. 1975;14(4):286-292.

18. Dijkstra BG, Ruijter JM, Hoyng PF. Outflow characteristics of isolated anterior segments of human eyes. Invest Ophthalmol Vis Sci. 1996;37(10):2015-2021.

19. Vass C, Hirn C, Unger E, et al. Human aqueous humor viscosity in cataract, primary open angle glaucoma and pseudoexfoliation syndrome. Invest Ophthalmol Vis Sci. 2004;45:E-abstract 5030.

20. Brubaker RF. Measurement of aqueous flow by fluorophotometry. In: Ritch R, Shields MB, Krupin T, editors. The Glaucomas. St Louis: Mosby; 1989:337-344.

21. Epstein DL. Schlemm canal surgery. Glaucoma Today. 2013 September/ October:46-49.

22. Rosenquist R, Epstein D, Melamed S, Johnson M, Grant WM. Outflow resistance of enucleated eyes at two different perfusion pressures and different extents of trabeculotomy. Curr Eye Res. 1989;8(12): $1233-1240$
Clinical Ophthalmology

\section{Publish your work in this journal}

Clinical Ophthalmology is an international, peer-reviewed journal covering all subspecialties within ophthalmology. Key topics include: Optometry; Visual science; Pharmacology and drug therapy in eye diseases; Basic Sciences; Primary and Secondary eye care; Patient Safety and Quality of Care Improvements. This journal is indexed on

\section{Dovepress}

PubMed Central and CAS, and is the official journal of The Society of Clinical Ophthalmology (SCO). The manuscript management system is completely online and includes a very quick and fair peer-review system, which is all easy to use. Visit http://www.dovepress.com/ testimonials.php to read real quotes from published authors. 